\title{
Miradas traductoras de geografía variable
}

\section{A Translation View with Variable Geography}

\section{PREFACIO}

\section{Silvia RoISS y Cristina VALDERREY REÑONES}

Universidad de Salamanca

roiss@usal.es / valderrey@usal.es

Recibido febrero-2019. Revisado: marzo-2019. Aceptado: mayo-2019.

Universidad de Boğaziçi (Estambul, Turquía), Universidad Complutense de Madrid (España), Universidad de Free State (Bloemfontein, Sudáfrica), Universidad Gaston Berger (Saint Louis, Senegal), Universidad de Islandia (Reikjavik, Islandia), Universidad de Juntendo (Tokio, Japón), Universidad Johannes Gutenberg (Maguncia, Alemania), Universidad de Las Palmas de Gran Canaria (España), Universidad de Mons (Bélgica), Universidad Rey Juan Carlos I (Madrid, España), Universidad de Salamanca (España). Definitivamente, este número de CLINA (vol. 5, n. ${ }^{\circ}$ ) es un número viajero. Un número de geografía variable tanto en la procedencia de sus autores -reflejada en la larga lista de universidades que comparten páginas- como en los contextos culturales estudiados que brindan un apasionante recorrido analítico por tres continentes (África, Asia y Europa) en muy diferentes momentos históricos.

Por otra parte y en sintonía con lo anterior, los trabajos reunidos aquí componen un número de contornos temáticos manifiestamente variados (propaganda política, 
ideología, identidad, nacionalismo y sus vínculos con la traducción; traducción lírica; traducción misionera; literatura poscolonial africana y su traducción; traducción como recreación; autotraducción; traducción de literatura infantil y juvenil de temática árabe e islámica, etc.) que abren un abanico amplio en los planteamientos teóricos y los enfoques metodológicos manejados por los distintos estudiosos (sin ánimo de exhaustividad: análisis del discurso, estudio historiográfico, funcionalismo, hibridismo, mediación lingüística, paratextualidad, post-traducción, transculturalidad y sociológica de la traducción). El hecho de reunir toda esta diversidad en un único volumen obedece al deseo de ofrecer una panorámica vasta de distintas miradas traductoras que convergen en una meta compartida: proponer una lectura de acercamiento múltiple a la complejidad y riqueza de perspectivas que encierra el estudio de la traducción en nuestros días.

El volumen se inicia con tres novedosas contribuciones cuyo eje vertebrador es el mundo asiático. En la primera, Kevin Henry (Universidad de Mons, Bélgica) sostiene que la publicación de las versiones oficiales al inglés y al francés de La gobernanza de China, una recopilación de los discursos del presidente Xi Jinping, reafirma la importancia de la traducción en las políticas diplomáticas y culturales del gigante asiático. Henry combina lo sociológico con lo ideológico para comparar las dos versiones con el original chino a la luz de las vertientes descriptiva y funcionalista de la traducción, incorporando planteamientos del análisis crítico del discurso (entre otros: audiencia, ethos, pathos y dispositivos retóricos). En las otras dos aportaciones, Yingjie Zhang (Universidad Johannes Gutenberg, Alemania) y Mutsuko Tsuboi (Universidad de Juntendo, Japón) profundizan en algunas de las variaciones que permiten perfilar el escurridizo tema de la identidad en traducción. Para Tsuboi, las nociones de nacionalismo y etnicidad ocupan un espacio creciente en el mundo y corren paralelas a los movimientos globalizadores. Ilustra esta idea centrando su exposición en el Japón de los últimos años del siglo XIX, cuando se logra establecer un Estado nacional moderno que da lugar a la formación de una identidad nacional japonesa. A través del análisis de textos escritos y traducidos por élites académicas que desempeñaron un papel importante en los principales movimientos nacionalistas, explora el modo en que las prácticas traductoras y los aspectos ideológicos del período se interrelacionaron para conformar el nacionalismo japonés en ese momento. Como contrapunto a este nacionalismo identitario, la propuesta de Zhang pone el foco en la idea de identidad fragmentada y se centra en la traducción de la transculturalidad. Su artículo parte de los diarios de John Rabe, responsable alemán del Comité Internacional para la Zona de Seguridad de la ciudad ocupada de Nanking en la Segunda Guerra Mundial, y sus traducciones al chino y al inglés a finales de la década de 1990. Busca mostrar que el significado creado en un contexto transcultural tiende a someterse a una mediación selectiva cada vez que se traduce.

Las aportaciones de Cristina Naupert (Universidad Rey Juan Carlos I, España) y de Alaz Pesen (Universidad de Boğaziçi, Turquía) tienen como trasfondo común la

Silvia ROISS y Cristina VALDERREY REÑONES Miradas traductoras de geografía variable 
importancia de la historiografía en la comprensión del fenómeno traductor, si bien sus estudios se centran en contextos culturales y temporales muy alejados entre sí. Naupert ofrece un interesante análisis del marco de comunicación multilingüe y multicultural que se configura entre misioneros europeos e indígenas amerindios a lo largo del proceso colonizador en las tierras de Brasil. Para ello revisa el término «traducción sin original textualizado» que resulta imprescindible para el estudio historiográfico de la traducción misionera en la época de expansión colonial europea. En segundo lugar, considera la (no) sostenibilidad cultural del proceso misionero-evangelizador por parte de los jesuitas en Brasil. Pesen, por su parte, se centra en la cultura turca y examina la era aranjman. El término se refiere a la introducción, en los años 1960, de la música pop extranjera en Turquía y a su adaptación cultural al contexto histórico-político imperante. Esboza un marco teórico que fusiona los conceptos de invención, importación y repertorio cultural de Even-Zohar con la noción de reescritura de Lefevere. El estudio subraya la importancia de un enfoque holístico de la traducción de canciones.

El variado repertorio temático de este número se articula a partir de este momento en torno a la traducción literaria declinada en muy diferentes claves analíticas. Así, las tres contribuciones siguientes recorren la traducción de lo literario desde planteamientos que aplican el concepto de hibridismo, ahondan en la noción de polisistema o avanzan en el terreno de la post-traducción. En primer lugar, Isabel Pascua Febles (Universidad de Las Palmas de Gran Canaria, España) y Alba Rodríguez-García (Universidad Gaston Berger, Senegal) realizan un análisis traductológico contrastivo de dos novelas de autoras poscoloniales africanas -la senegalesa Ken Bugul y la nigeriana Buchi Emecheta- escritas en lenguas europeas coloniales y sus respectivas traducciones al español. Asumen que estas obras están escritas en lenguajes híbridos, africanos en su fondo y europeizados en su forma, que poseen particularidades lingüísticas muy específicas y numerosas referencias culturales que suponen un escollo para su traducción. Desde una mirada mujerista, buscan mostrar cómo a través de esta forma de escribir, las dos escritoras presentan su cultura, su lenguaje híbrido y una identidad africana-femenina fragmentada. A continuación, Beatriz Soto (Universidad de Rey Juan Carlos I, España) presenta las normas preliminares de traducción de literatura infantil y juvenil de temática árabe e islámica, definidas a partir de un estudio de corpus formado por 150 obras publicadas con esta temática en España. Analiza las interacciones del polisistema literario español con otros polisistemas occidentales, en el marco del sistema literario mundial (Casanova y Heilbron/Sapiro). También aborda el papel de las editoriales españolas como parte del mecenazgo (Lefevere), y su función en la conservación/renovación de la poética del polisistema literario meta y en la conformación de la Otredad en la cultura española. Cristina Carrasco (Universidad de Salamanca, España) se adentra, a su vez, en la era de la posttraducción. Toma como referencia los planteamientos de Cixous y de Barthes partiendo de la idea de que el cuerpo, en tanto que sistema semiótico, puede traducirse. Su aportación, por lo tanto, se enmarca en las últimas corrientes de los Estudios de Traducción, 
que proponen el uso de enfoques que miren hacia fuera (Bassnett y Bassnett/Johnston) y que estudien textos que hasta el momento no se han considerado traducciones en sentido clásico (Gentzler). Para desarrollar esta idea, analiza las reescrituras del cuerpo femenino en las novelas El último patriarca, La hija extranjera y Madre de leche y miel, de la escritora española de origen marroquí Najat El Hachmi.

Las contribuciones de Cornelia Goldenhuys (Universidad Free State, Sudáfrica), Mónica Fuentes del Río (Universidad Complutense de Madrid, España) y Marion Lerner (Universidad de Islandia, Islandia) siguen moviéndose en el campo de la traducción literaria y abordan cuestiones como la autotraducción, la recreación o la (in)visibilidad del traductor. El propósito de Goldenhuys es investigar si un traductor, como ocurre con el autor de una obra de ficción original, deja un rastro distintivo único en su propio estilo de escritura. Pretende demostrar que el autor sudafricano Brink -traductor del afrikáans al inglés tanto de su propia obra como de obras de otros autores- muestra una preferencia por el uso de elementos léxicos específicos, patrones sintácticos, dispositivos cohesivos, puntuación etc. donde otras opciones podrían estar igualmente disponibles en el idioma. Confirma, por lo tanto, que existen estilos de traducción individuales, independientemente de los universales generalmente aceptados. Por su parte, Fuentes del Río analiza en su artículo la labor de Carmen Martín Gaite como traductora. Labor que se enriquece y retroalimenta con sus otras facetas creadoras, sobre todo, como crítica literaria y novelista. Para la escritora, el papel del traductor es doble: por una parte, es lector de la obra original -su lectura ha de ser minuciosa y exhaustiva-; y, por otra, es escritor del nuevo texto en otra lengua. Así pues, la traducción es, para Martín Gaite, la recreación de la obra, su versión, su interpretación a otro idioma. Por ello, al traductor se le deben exigir ciertos requisitos imprescindibles para realizar su trabajo de forma certera, algunos de los cuales coinciden con las cualidades del escritor. Cierra este último bloque Lerner que se ocupa de la cuestión de la (in)visibilidad del traductor. Analiza las traducciones del islandés al alemán de Josef Calasanz Poestion de la primera novela islandesa Piltur og stúlka von Jón Thoroddsen (1850, 1867²). Poestion subordinó sus traducciones a un objetivo textual: que el público alemán se familiarizara con las costumbres y tradiciones del pueblo islandés para que se hiciera una idea de la, hasta ese momento, desconocida literatura islandesa. Para ello se sivvió en sus traducciones de una serie de peritextos y epitextos que demuestran la autoridad pedagógica del traductor.

En un momento en el que la perspectiva interdisciplinar y la pluralidad de enfoques teóricos y metodológicos son señas de identidad de nuestro campo de estudio, solo nos resta agradecer a todos los autores que han participado en la publicación su esfuerzo para que este número de CLINA vea la luz, a la vez que su talentosa labor para dirigir nuestras miradas traductoras de geografía variable hacia la Traductología de hoy y sus desafíos futuros.

Las editoras

Silvia ROISS y Cristina VALDERREY REÑONES Miradas traductoras de geografía variable

\section{CLINA}

vol. 5-1, Junio 2019, 7-10

eISSN: 2444-1961

Ediciones Universidad de Salamanca - CC BY-NC-ND 